\title{
2D Investigation of Bonding Forces of Straight Steel Fiber in Concrete
}

\author{
Amjad Khabaz \\ Civil and Environmental Engineering Department, College of Engineering, Majmaah University, Riyadh, KSA \\ Email: a.khabaz@mu.edu.sa
}

Received 2 October 2015; accepted 17 October 2015; published 23 October 2015

Copyright (C) 2015 by author and OALib.

This work is licensed under the Creative Commons Attribution International License (CC BY). http://creativecommons.org/licenses/by/4.0/

(c) (i) Open Access

\section{Abstract}

The joint behavior of steel fiber and concrete in Steel Fiber Reinforced Concrete (FRC) member is based on the fact that a bond is maintained between the two materials after the concrete hardens. If a straight steel fiber is embedded into concrete, a considerable force is required to pull the steel fiber out of the concrete. If the embedded length of the steel fiber is enough, the steel fiber may yield, leaving some length of the fiber in the concrete. The bonding force depends on the friction between the steel fiber and the concrete. It is influenced mainly by the shape of steel fiber and the concrete mix properties. The effect of parameters such as end condition of fiber (smooth or hooked-end), embedment length, (W/C) ratio, paste phase of FRC, steel-micro fiber, and curing conditions on fiber-matrix pull-out behavior must be determined. By considering the friction at the fiber-matrix interface during the fiber extraction process, analytical models which consider Poisson's effects on both fiber and matrix might be developed, and knowledge of the initial extraction stress of the fiber provides the residual normal stress at the fiber-matrix interface. The importance of this research lies in possibility to evaluate the bonding and friction forces of steel fiber in Steel Fiber Reinforced Concrete (SFRC) in the case of straight steel fiber. This evaluation will be done using 2D computer simulations including bonding and friction forces at the interfacial surface between the straight steel fiber and the concrete.

\section{Keywords}

Concrete, Fiber Reinforced Concrete (FRC), Steel Fiber Reinforced Concrete (SFRC), Straight Steel Fiber, Bonding Forces, Friction Forces, Pull-Out

Subject Areas: Civil Engineering, Composite Material

\section{Introduction}

Researchers cover experimentally the main part of shear stresses which are used to evaluate the pull-out resis- 
tances of single fiber embedded into hardened matrix of concrete or some other materials, and most results are obtained depending on these stresses, "as discussed by Khabaz [1] [2], Hull \& Clyne [3], and Kim \& El-Tawil \& Naaman [4]"; while some researchers refer to bonding forces without real or numerical calculations, "as discussed by Krasnikovs \& Lapsa \& Eiduks [5], Krasnikovs \& Khabaz \& Shahmenko \& Lapsa [6], Krasñikovs \& Kononova \& Khabaz \& Vība [7], Tuyan \& Yazici [8], Zhandarov, Mäder [9] and Barbosa \& Filho [10]”; therefore this research will continue these cumulative investigations to obtain numerical methods using computer simulations including the bonding and friction forces at the interfacial surface between straight steel fiber and the concrete.

In the case of using straight steel fiber (see Figure 1) as reinforcement material to improve the resistance capacity of plain concrete under axial or flexural tension forces to obtain Steel Fiber Reinforced Concrete (SFRC), "as discussed by Khabaz [1] [12]"; bonding forces at the interface between the steel fiber and the concrete matrix must be satisfactory, "as discussed by Khabaz [2]". Bonding forces between these two materials are generated due to friction forces at the interface, "as discussed by Khabaz [2]"; therefore, the final evaluation of the bonding forces is related with the real value of the friction forces, consequently the friction coefficient value between straight steel fiber and the concrete is important to evaluate and calculate the real value of the friction forces. Therefore, computer simulations might be created using same experimental data such as Elasticity Modulus and Poisson's Ratio, "as discussed by Koyanagi \& Nakatani \& Ogihara [13] and Bilisik [14]”; thus in the case of straight steel fiber we need to create 2 types of computer simulations, the first type represents the initial stage of perfect bond between the fiber and the concrete, and the second type is referred to frictional sliding of straight steel fiber during the extracting process from the concrete, "as discussed by Khabaz [1], Li \& Liu \& Peng \& Yan \& Liu \& Hu [15] and Alam \& Lo \& Karim [16]”; then, we need to use and analyze contact element model "as discussed by Banholzer \& Brameshuber \& Jung [17], Kim \& El-Tawil, \& Naaman [18], Mpalaskas \& Vasilakos \& Matikas \&Chai [19] and Beckert \& Lauke [20]”.

Contact problems present two significant difficulties. First, you generally do not know the regions of contact until you've run the problem. Depending on the loads, material, boundary conditions, and other factors, surfaces can come into and go out of contact with each other in a largely unpredictable and abrupt manner. Second, most contact problems need to account for friction. There are several friction laws and models to choose from, and all are nonlinear. Frictional response can be chaotic, making solution convergence difficult.

Contact problems fall into two general classes: rigid-to-flexible and flexible-to-flexible. In rigid-to-flexible contact problems, one or more of the contacting surfaces are treated as rigid (i.e., it has a much higher stiffness relative to the deformable body it contacts). In general, any time a soft material comes in contact with a hard material, the problem may be assumed to be rigid-to-flexible. Many metal forming problems fall into this category. The other class, flexible-to-flexible, is the more common type. In this case, both (or all) contacting bodies are deformable (i.e., have similar stiffnesses).

In this investigation 2D finite element models representing real laboratory samples will be created, where steel mould will be used in the lab to cast the samples during the experimental program (see Figure 2); consequently precise description of mechanical behavior of straight steel fiber in the concrete might be observed. Comparison between pull-out experimental results of straight steel fiber and stress distribution of finite element models will lead to understand the benefits of using steel fiber with sophisticated form as well as to achieve concrete mixes providing enough bonding with steel fibers, and to improve the participation of friction forces in resistance of the applied pull-out load through development process of the built environment between the steel fiber and the concrete.

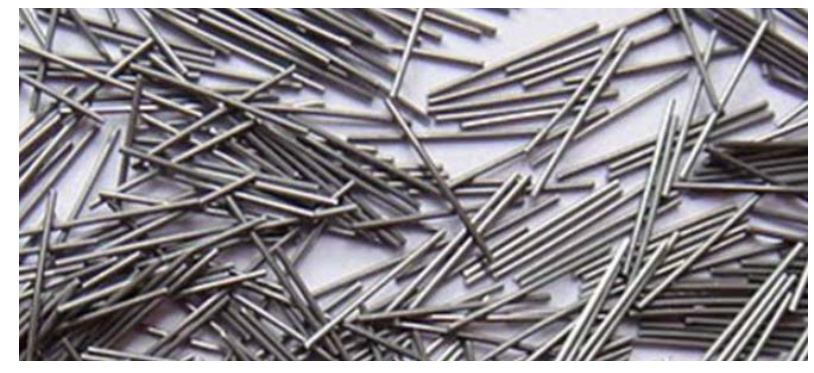

Figure 1. Straight steel fibers [11]. 


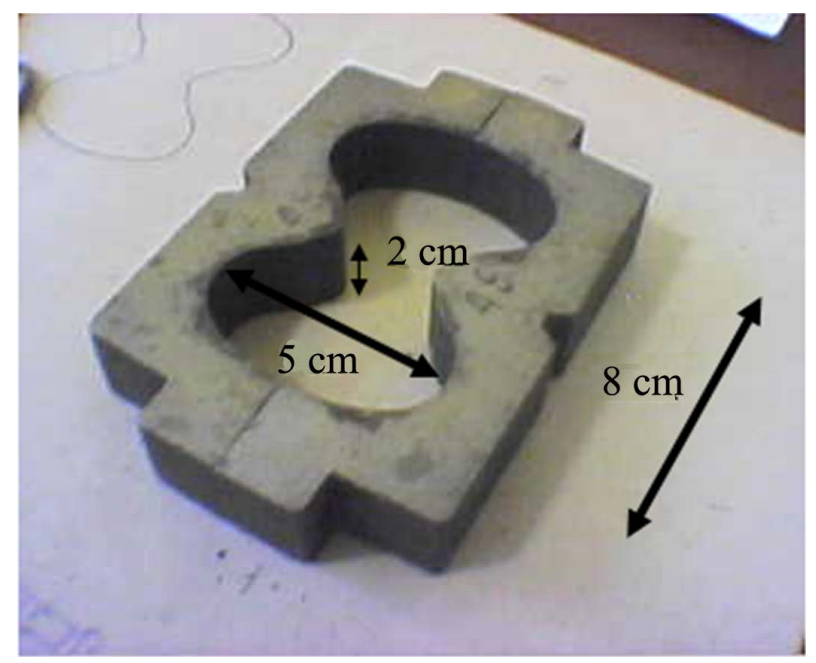

Figure 2. Steel mould used to prepare pull-out sample [12].

\section{Materials and Methods}

\subsection{A Critical Review of SFRC Modeling Techniques}

The ultimate purpose of a finite element analysis is to recreate mathematically the behavior of an actual engineering system. In other words, the analysis must be an accurate mathematical model of a physical prototype. In the broadest sense, this model comprises all the nodes, elements, material properties, real constants, boundary conditions, and other features that are used to represent the physical system.

In ANSYS terminology, the term model generation usually takes on the narrower meaning of generating the nodes and elements that represent the spatial volume and connectivity of the actual system. Thus, model generation in this discussion will mean the process of defining the geometric configuration of the model's nodes and elements.

The ANSYS program offers the following approaches to model generation:

- Creating a solid model within ANSYS.

- Using direct generation.

- Importing a model created in a computer-aided design (CAD) system.

\subsection{Simulations of Pull-Out Test}

Various programming simulations as a virtual samples using finite element method will be created to represent the mechanism of extracting straight steel fiber from concrete matrix under special conditions. Creation of the finite element models must be started by determination the properties of materials which will be used, in our simulations we have only two materials (steel fiber and concrete) (see Figure 3).

Elasticity modulus E and Poison's ratio $v$ of the concrete matrix and steel fiber are used in simulations as follows:

Concrete matrix $\mathrm{E}=30,000 \mathrm{MPa}, v=0.2$.

Steel fiber $\mathrm{E}=200,000 \mathrm{MPa}, v=0.2$.

Simulation is created using friction coefficient between straight steel fiber and concrete equal to 0.1 , and the embedded length of steel fiber in the concrete equal to $0.5 \mathrm{~L}$, where $\mathrm{L}=5 \mathrm{~cm}$ (total length of straight steel fiber), and fiber diameter equal to $0.8 \mathrm{~mm}$ (see Figure 4).

\subsection{Experimental Program of Pull-Out Test and Results}

An experimental samples of single straight steel fiber (Length $\mathrm{L}=5 \mathrm{~cm}$, Diameter $=0.8 \mathrm{~mm}$ ) are prepared in the lab, where the single steel fiber is embedded using different length ratio $(0.1 \mathrm{~L}, 0.2 \mathrm{~L}, 0.3 \mathrm{~L}, 0.4 \mathrm{~L}, 0.5 \mathrm{~L})$ respectively into concrete matrix, and the concrete matrix is prepared according to the concrete mix components as shown in the Table 1. 


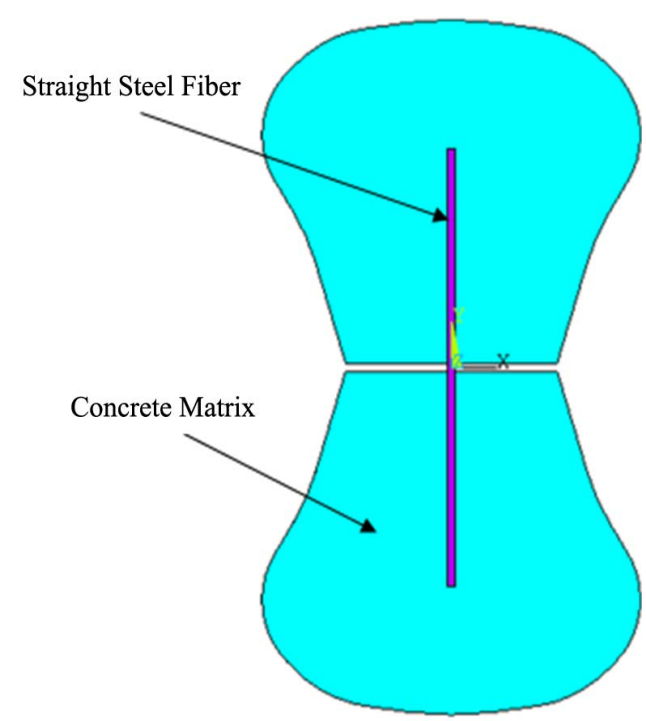

Figure 3. Materials of the finite element model.

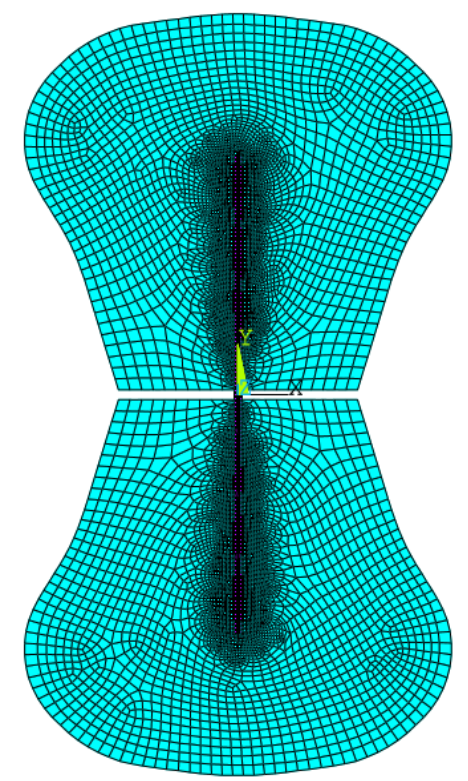

Figure 4. Finite element model.

Stress-displacement curves are obtained according to pull-out test (see Figure 5, and Figure 6), where the forces converted to be stresses.

\section{Results and Discussion}

Fiber pull-out experimental results are crucial for FRC mix design and preparation, therefore the important factor is the ability to produce (mix) the material with desired properties. There are several technological aspects like workability, flowability of the concrete mix that very often limit theoretical possibilities of this material in practical applications. In order to avoid problems with workability and similar, special mix design programme has been developed for steel fiber reinforced concrete which allows high fractions of steel fibers to be mixed in the mix during preparation (see Table 1).

For embedded lengths less than half of a fiber length $\left(\mathrm{L}_{\mathrm{b}}<0.5 \mathrm{~L}\right)$ no fiber breaking was encountered (with exceptions for some distinct samples) with the vast majority of tested fibers pulling out (see Figure 6). At 
Table 1. Components of concrete matrix used in pull-out tests.

\begin{tabular}{ccc}
\hline Designation & F50a & 1 liter \\
\hline Components & $\mathbf{1} \mathbf{~ m}^{\mathbf{3}}$ & \\
CEM II $42.5 \mathrm{~A}-\mathrm{V}$ & & 556.00 \\
Sand 0.3/2.5 mm & 556 & 863.00 \\
Sand 0/0.5 mm & 863 & 288.00 \\
Filler (Dolomite powder) & 288 & 150.00 \\
Microsilica & 150 & 81.00 \\
Water & 81 & 247.00 \\
SIKA EVO 26 & 247.0 & 9.00 \\
SIKA AER S (10\%) & 9.00 & 2.00 \\
Fiber & 2.00 & 2196.00 \\
Straight steel & & 0.00 \\
Total fibers: & 0.00 & 0.00 \\
Fibers (\%) & 0.00 & 0.00 \\
Total & 0.00 & 2196.00 \\
\hline
\end{tabular}

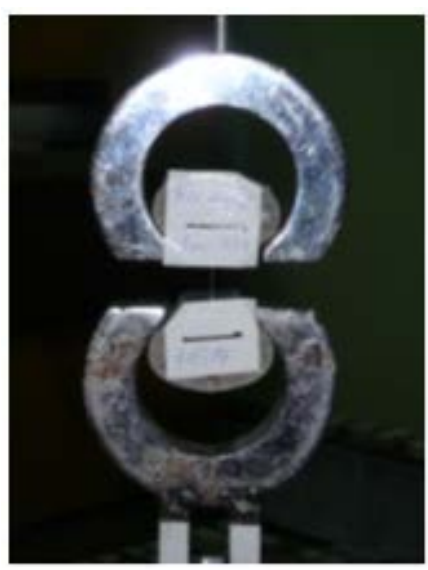

Figure 5. Pull-out experiment set-up.

extremely small embedded lengths the character of the pull-out curve changes completely as the pull-out occurs without fiber straightening because the concrete matrix fails due to overload from stress concentration.

Maximum pull-out resistance from experimental results have been obtained using embedded length equal to $0.5 \mathrm{~L}$, therefore if the use of similar applied load and dispalcement in the comupter simulations will give us YStress distribution during pull-out test for each material, the single straight steel fiber and the concrete (see Figure 7(a), Figure 7(b)), thus the maximum bonding between the fiber and the concrete is reached where the embedded lenght reach $0.5 \mathrm{~L}$.

Observing the single straight steel fiber under pull-out tests in both programs, the experimental and the coputer simulation, lead to say that bonding forces between the fiber and the concrete can be evaluated during extracting behavior of the fiber from the concrete using pull-out test according to three stages, the first stage represents the case of perfect adhesion mode where the bonding forces resist the applied tension load which is trying to extract the fiber from the concrete (see Figure 8), second stage might be named as debonding stage 


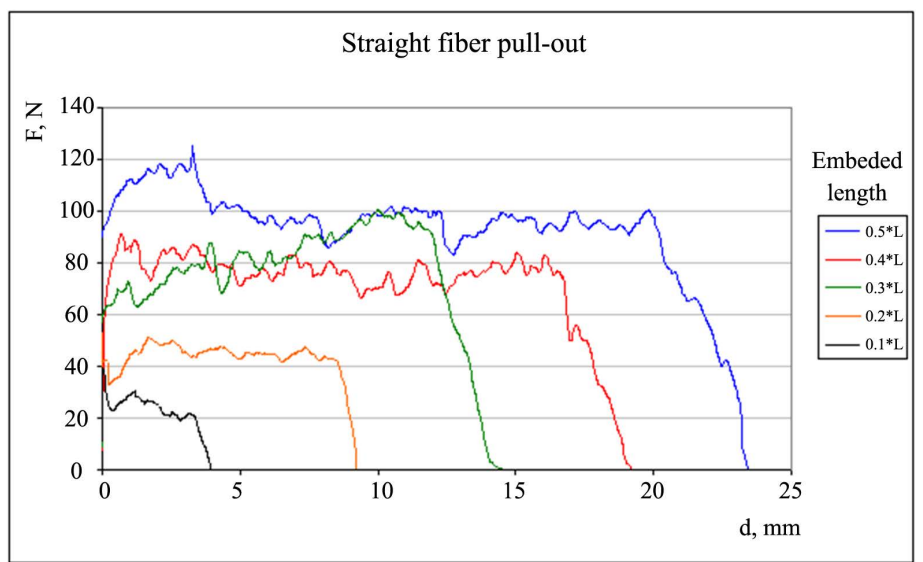

Figure 6. Pull-out curves of straight Steel fiber embedded 0.1L, 0.2L, 0.3L, 0.4L, 0.5L respectively into concrete matrix, where $\mathrm{L}=5 \mathrm{~cm}$.

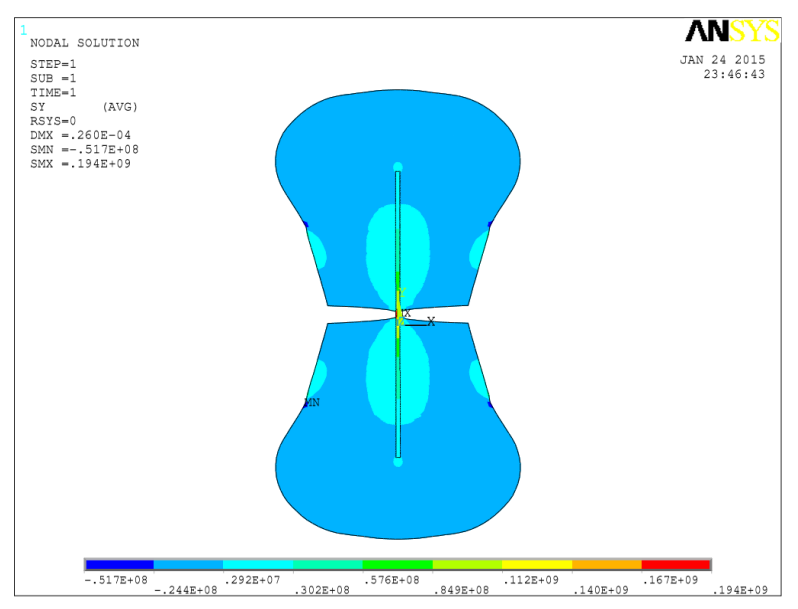

(a)

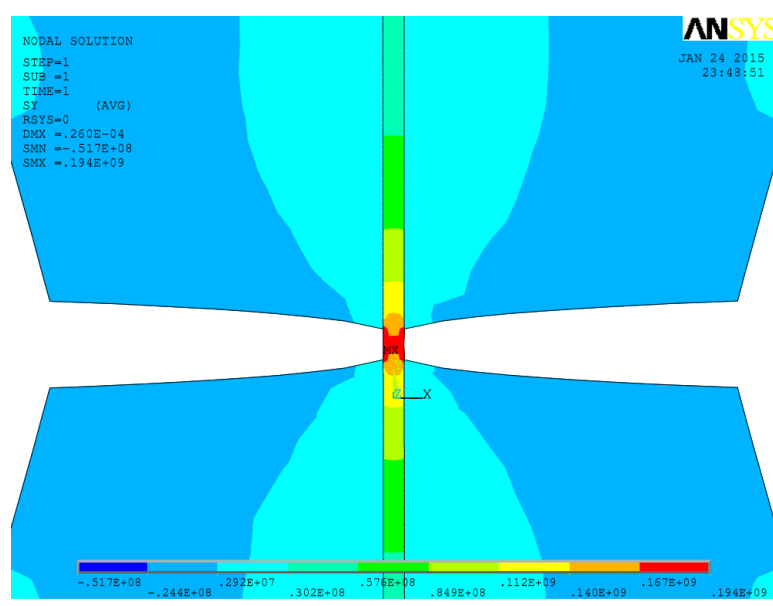

(b)

Figure 7. (a) (b) Y-Stress distribution under pull-out using tensile force equal to $115.7 \mathrm{~N}$ and displacement equal to 0.026 $\mathrm{mm}$.

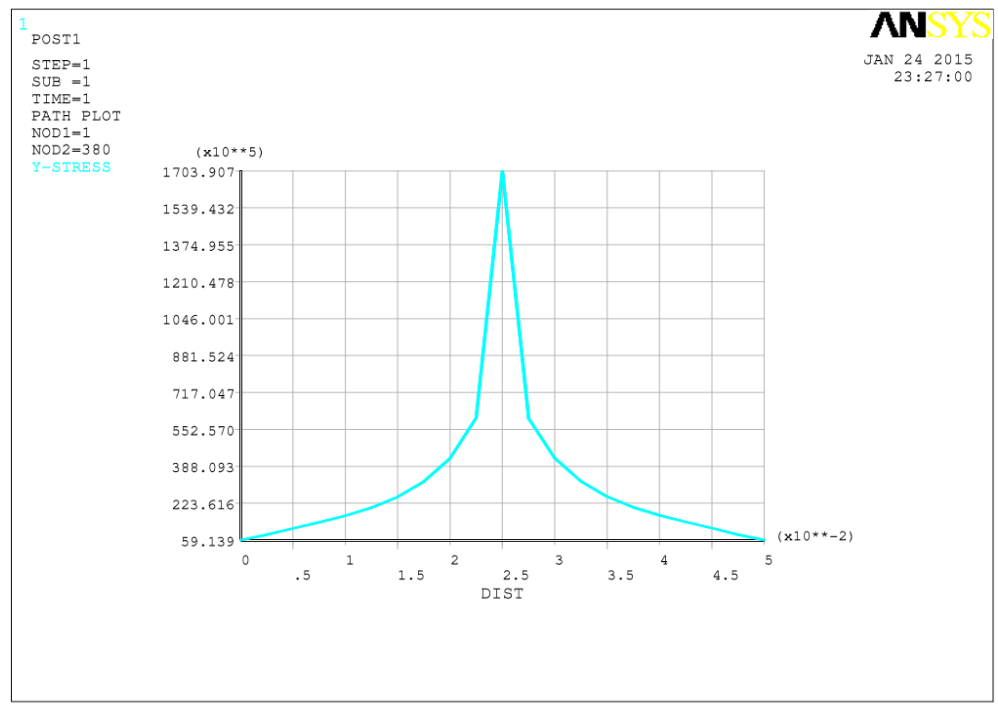

Figure 8. Frictional sliding behavior of straight steel fiber after losing bonding forces. 


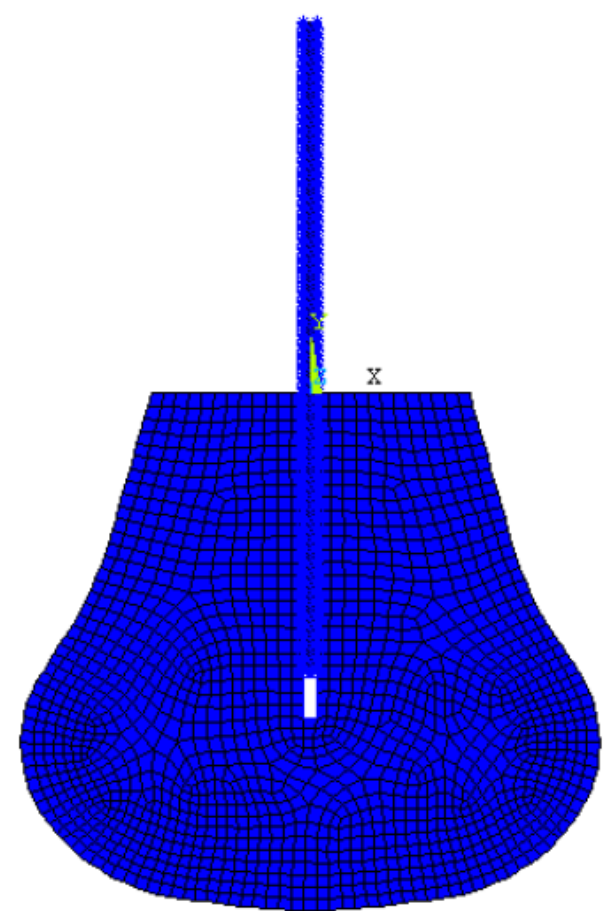

Figure 9. Frictional sliding behavior of straight steel fiber after losing bonding forces.

starts when the tension applied load reaches critical value where the bonding strength starts to diminish, then partial debonding progressively appears at the interface until full interfacial debonding situation happens, then the third pull-out stage starts where the frictional sliding mode can be shown (see Figure 9), this third stage is necessary to calculate the friction factor during the outwards-sliding motion of the fiber from the concrete matrix.

\section{Conclusions}

- Straight steel fibers showed weak bonding forces and friction forces during fiber slide-out.

- Linear elastic behaviour of the fiber-matrix system is interrupted by interface debonding which occurs due to overall weak bonding between the concrete matrix and the surface of the steel fiber.

- The surrounding concrete matrix must have sufficiently enough strength to resist stress concentration at fiber edges.

- If surrounding concrete matrix is weak, the stress concentration causes failure of the brittle matrix and no pull-out resistance is obtained.

- Concrete matrix failure (spalling) is more likely to happen for cases with larger fiber diameters.

- The fiber-matrix bond characteristics improved as the embedment length of fiber increased, especially for smooth fiber.

- Increasing the diameter of the fiber and improving the curing conditions increased matrix-fiber bond.

- Low W/C ratio, which enhances the bond strength, reduces the importance of embedment length of the hooked-end fiber. Furthermore, the pull-out peak load and debonding toughness increased as the W/C ratio decreased in the all curing conditions.

\section{References}

[1] Khabaz, A. (2015) Determination of Friction Coefficient between Straight Steel Fiber and the Concrete Fri (SSF.C). Advances in Materials, 4, 20-29. http://dx.doi.org/10.11648/j.am.20150402.11

[2] Khabaz, A. (2015) Impact of Fiber Shape on Mechanical Behavior of Steel Fiber in Fiber Reinforced Concrete FRC. World Journal of Engineering and Physical Sciences, 3, 1-6. 
[3] Hull, D. and Clyne, T.W. (1996) An Introduction to Composite Materials. 2nd Edition, Cambridge University Press, Cambridge. http://dx.doi.org/10.1017/CBO9781139170130

[4] Kim, D.J., El-Tawil, S. and Naaman, A.E. (2008) Loading Rate Effect on Pullout Behavior of Deformed Fibers. ACI Materials Journal, 105, 576-584.

[5] Krasnikovs, A., Lapsa, V. and Eiduks, M. (2007) Non-Traditional Reinforcement for Concrete Composites—State of the Art. Riga Technical University, Latvia.

[6] Krasnikovs, A., Khabaz, A., Shahmenko, G. and Lapsa, V. (2008) Glass and Carbon Fiber Concrete Micromechanical and Macromechanical Properties. Proceedings of Riga Technical University, Transport and Engineering, 28, 132-141.

[7] Krasņikovs, A., Kononova, O., Khabaz, A. and Vība, J. (2010) Fiber Concrete Non-Linear Fracture Control through Fresh Concrete Flow Numerical Simulation. Journal of Vibroengineering, 12, 149-160.

[8] Tuyan, M. and Yazici, H. (2012) Pull-Out Behavior of Single Steel Fiber from SIFCON Matrix. Construction and Building Materials, 35, 571-577. http://dx.doi.org/10.1016/j.conbuildmat.2012.04.110

[9] Zhandarov, S. and Mäder, E. (2014) An Alternative Method of Determining the Local Interfacial Shear Strength from Force-Displacement Curves in the Pull-Out and Microbond Tests. International Journal of Adhesion \& Adhesives, 55, 37-42. http://dx.doi.org/10.1016/j.ijadhadh.2014.07.006

[10] Barbosa, M.T.G. and Filho, S.S. (2013) Investigation of Bond Stress in Pull out Specimens with High Strength Concrete. Global Journal of Researches in Engineering Civil and Structural Engineering, 13.

[11] Online Images. http://dmvplus.pl/images/stories/produkty/wlokna_stalowe/krampeharex/dg_male.jpg

[12] Khabaz, A. (2014) Non-Metallic Fiber Reinforced Concrete. LAP LAMBERT Academic Publishing. ISBN 978-3-65950914-8.

[13] Koyanagi, J., Nakatani, H. and Ogihara, S. (2012) Comparison of Glass-Epoxy Interface Strengths Examined by Cruciform Specimen and Single-Fiber Pull-Out Tests under Combined Stress State. Composites: Part A, 43, 1819-1827. http://dx.doi.org/10.1016/j.compositesa.2012.06.018

[14] Bilisik, K. (2011) Properties of Yarn Pull-Out in Para-Aramid Fabric Structure and Analysis by Statistical Model. Composites: Part A, 42, 1930-1942. http://dx.doi.org/10.1016/j.compositesa.2011.08.018

[15] Li, Y., Liu, Y.L., Peng, X.H., Yan, C., Liu, S. and Hu, N. (2011) Pull-Out Simulations on Interfacial Properties of Carbon Nanotube-Reinforced Polymer Nanocomposites. Computational Materials Science, 50, 1854-1860. http://dx.doi.org/10.1016/j.commatsci.2011.01.029

[16] Alam, Md.J.I., Lo, S.R. and Karim, M.R. (2014) Pull-Out Behaviour of Steel Grid Soil Reinforcement Embedded in Silty Sand. Computers and Geotechnics, 56, 216-226. http://dx.doi.org/10.1016/j.compgeo.2013.12.004

[17] Banholzer, B., Brameshuber, W. and Jung, W. (2005) Analytical Simulation of Pull-Out Tests-The Direct Problem. Cement and Concrete Composites, 27, 93-101. http://dx.doi.org/10.1016/j.cemconcomp.2004.01.006

[18] Kim, D.J., El-Tawil, S. and Naaman, A.E. (2010) Effect of Matrix Strength on Pullout Behavior of High Strength Deformed Steel Fibers. In: Parra-Montesinos, G.J. and Balaguru, P., Eds., Antoine E. Naaman Symposium-Four Decades of Progress in Prestressed Concrete, Fiber Reinforced Concrete, and Thin Laminate Composites, ACI Special Publication 2010, SP 72, 135-150.

[19] Mpalaskas, A.C., Vasilakos, I., Matikas, T.E., Chai, H.K. and Aggelis, D.G. (2014) Monitoring of the Fracture Mechanisms Induced by Pull-Out and Compression in Concrete. Engineering Fracture Mechanics, 128, 219-230. http://dx.doi.org/10.1016/j.engfracmech.2014.07.020

[20] Beckert, W. and Lauke, B. (1996) Finite Element Calculation of Energy Release Rate for Single-Fibre Pull-Out Test. Computational Materials Science, 5, 1. http://dx.doi.org/10.1016/0927-0256(95)00052-6 